\title{
Assessment of risk factors for non-specific chronic disabling low back pain in Japanese workers-findings from the CUPID (Cultural and Psychosocial Influences on Disability) study
}

\author{
Ko MATSUDAIRA ${ }^{1 *}$, Masaya TAKAHASHI ${ }^{2}$, Mika KAWAGUCHI ${ }^{3}$, \\ Ayumi HAMAGUCHI ${ }^{3}$, Yuri HAGA ${ }^{3}$ and Tadashi KOGA ${ }^{3}$

\begin{abstract}
${ }^{1}$ Department of Medical Research and Management for Musculoskeletal Pain, 22nd Century Medical \& Research Center, Faculty of Medicine, The University of Tokyo, Japan

${ }^{2}$ Occupational Epidemiology Research Group, National Institute of Occupational Safety and Health, Japan

${ }^{3}$ Clinical Study Support, Inc., Japan
\end{abstract}

Received August 6, 2018 and accepted October 11, 2018

Published online in J-STAGE October 19, 2018

\begin{abstract}
The majority of patients with non-specific low back pain (LBP) suffer from chronic pain. Psychosocial factors play an important role in the chronicity of LBP. To explore the risk factors for chronic disabling LBP in detail, we assessed its various risk factors in Japanese workers, using data from the Cultural and Psychosocial Influences on Disability (CUPID) study. Data were drawn from a $1 \mathrm{yr}$ follow-up of 20-59 yr-old workers who participated in the CUPID study. A self-administered questionnaire assessed various factors, including individual characteristics, ergonomic work demands, and work-related or other psychosocial factors. Logistic regression analyses were performed to assess the associations between these factors and chronic disabling LBP. Of 198 participants, 35 (17.7\%) had chronic disabling LBP during the $1 \mathrm{yr}$ follow-up. Multivariate logistic regression analysis revealed that the interaction effect of the two factors, expectation of LBP problems and excessive working hours ( $\geq 60 \mathrm{~h}$ per week), was associated with chronic disabling LBP. Chronic disabling LBP was present in $\mathbf{4 2 . 5 \%}$ of participants with both of these two risk factors, whereas it was present in $\mathbf{1 1 . 8 \%}$ of participants without these risk factors. In conclusion, among various factors, the combination of two psychosocial factors was particularly associated with chronic disabling LBP.
\end{abstract}

Key words: Non-specific low back pain, Risk factors, Japanese workers, Psychosocial factors, Chronicity

\section{Introduction}

Low back pain (LBP) is a common condition. LBP has consistently ranked as the top leading cause of years lived

*To whom correspondence should be addressed.

E-mail: kohart801@gmail.com

(C)2019 National Institute of Occupational Safety and Health with disability globally in the last decades ${ }^{1)}$. LBP is also common in Japan; a national survey in 2016 reported that LBP was the most common health complaint among men, and the second most common complaint among women ${ }^{2}$. The lifetime prevalence of LBP in Japan was reported to be over $80 \%{ }^{3)}$.

The majority of patients with LBP have no identifiable underlying pathology, and approximately $85 \%$ of LBP cases are classified as non-specific $\mathrm{LBP}^{4,5)}$. One study re- 
ported that the recovery rate of non-specific LBP became substantially lower after 3 months, and $65 \%$ of patients with non-specific LBP still had pain at $1 \mathrm{yr}$ after onset ${ }^{6)}$. These findings suggest that non-specific LBP may not be successfully managed in primary care, and many patients may suffer from persistent pain and disability. Chronic LBP is associated with not only such a clinical burden but also a substantial economic burden in terms of both direct and indirect costs (e.g., work days lost) ${ }^{7,8)}$.

Psychosocial factors are known to play an important role in the chronicity of non-specific LBP. The factors include depression, somatization, fear-avoidance beliefs and behaviors, pain catastrophizing, pain perceptions and expectations $^{9,10)}$, low job satisfaction ${ }^{11-13)}$, and emotional trauma in childhood, such as abuse ${ }^{14)}$. Although the associations between these psychosocial factors and the chronicity of LBP have been reported in a number of studies of Western populations, few studies have examined this issue in the Japanese population. Because cultural differences can influence the impact of psychosocial factors, it is important to investigate the associations between these factors and the chronicity of LBP in the Japanese population.

In a previous study, we assessed the associations between psychosocial factors and chronic disabling LBPpersisting for more than 3-months, and interfering with work-in Japanese workers ${ }^{15}$. The results suggested that a combination of psychosocial factors can increase the risk of chronic disabling $\mathrm{LBP}^{15}$.

In the current study, to corroborate our previous findings and explore the risk factors for chronic disabling LBP in further detail, we again assessed the various risk factors for chronic disabling LBP in Japanese workers using data from the Cultural and Psychosocial Influences on Disability (CUPID) study ${ }^{16-22)}$.

\section{Subjects and Methods}

\section{Data collection}

Data were drawn from a $1 \mathrm{yr}$ follow-up of participants in the CUPID study. The CUPID study aimed to explore the cultural and psychosocial influences on musculoskeletal disorders and associated disability in workers in various cultural environments. Participants in the CUPID study were workers aged 20-59 yr, recruited from 47 occupational groups in 18 countries. The methods of data collection in the CUPID study have been previously described $^{16)}$. In brief, in Japan participants were recruited from the following occupational groups in or near Tokyo: nurses, office workers (administrative and clerical work- ers), sales/marketing workers, and transportation workers (mainly truck drivers and pickup/delivery staff).

A self-administered questionnaire was distributed to 3,187 employees (1,074 nurses; 425 office workers; 380 sales/marketing workers; and 1,308 transportation workers), and respondents were asked to mail back the completed questionnaire directly to the study team. Of these, 2,651 employees returned the completed questionnaire (response rate $83.2 \%$ ). One year later, a follow-up questionnaire was distributed to these 2,651 participants. Of these, 1,809 participants returned the completed follow-up questionnaire.

The study was approved by the ethics committees of the University of Tokyo Hospital and the review board of the Japan Labour Health and Welfare Organization. Written informed consent was obtained from all participants.

\section{Baseline questionnaire}

The baseline questionnaire consisted of a Japanese translation of the original CUPID questionnaire ${ }^{16)}$ with additional questions for Japanese workers. The questionnaire assessed LBP in the past 12 months and the past month. LBP was defined as pain in an area between the inferior costal margin and gluteal folds. Pain associated with menstruation, pregnancy, or diseases involving fever was excluded. The severity of LBP was graded on a scale from 0 to 3 based on a scheme described by Von Korff et $a l .{ }^{23)}$ : grade 0 for "no LBP," grade 1 for "LBP that does not interfere with work," grade 2 for "LBP that interferes with work but causes no sick leave," and grade 3 for "LBP that interferes with work and causes sick leave."

The questionnaire also included items about the following ${ }^{21,22)}: 1$ ) individual characteristics (age, gender, obesity (body mass index $[\mathrm{BMI}] \geq 25 \mathrm{~kg} / \mathrm{m}^{2}$ ), smoking habits, hours of sleep, habitual exercise, age at which fulltime education was finished, past history of LBP, and tenure of current job); 2) ergonomic work demands in an average working day (keyboards use, wrist/finger movement, elbow bending, working with hands above shoulder height, lifting weights by hand, kneeling/squatting, standing, twisting back/stooping, and driving); 3) work-related psychosocial factors (working hours, work time shift, interpersonal stress at work, breaks, job control, support from others when at work, job satisfaction, and awareness of colleagues with LBP); and 4) other psychosocial factors (emotional trauma in childhood, somatizing tendency, mental health, and expectation of LBP problems).

Details of each factor assessment are reported elsewhere $^{22)}$. In brief, mental health was assessed using the relevant items from the MOS 36-item short-form health 
survey (SF-36) ver.1.2 $2^{24,25)}$, and a score of $\leq 52$ on the SF36 mental health scale, which is the cut-off point for depression in Japanese adults ${ }^{26}$, was defined as an indication of depressed mood (low mood). Somatizing tendency was assessed using items from the Brief Symptom Inventory $(\mathrm{BSI})^{27)}$, and was defined as being present if participants reported at least moderate distress in the past week for $\geq 2$ out of 5 somatic symptoms (faintness/dizziness, pains in the heart/chest, nausea/upset stomach, trouble getting breath, and hot/cold spells). The presence of expectations of LBP problems was assessed by a single question asking about the level of expectation of LBP problems in 12 months. Participants were interpreted as having expectations of LBP problems if they reported that LBP would "probably" or "definitely" become a problem in 12 months.

\section{Follow-up questionnaire}

The follow-up questionnaire included items asking about job change since the baseline assessment and LBP in the past 12 months and the past month. The severity of LBP was graded according to the same criteria (grade 0-3) as at baseline assessment.

\section{Data analysis}

For the outcome of interest, we assessed the participants who had chronic disabling LBP during the $1 \mathrm{yr}$ follow-up period. In the current study, we defined chronic disabling LBP as grade 2 or 3 of LBP that interfered with work regardless of whether it caused sick leave or not, which persisted for 3 months or longer ${ }^{15)}$. Participants were included in the analysis if they had disabling LBP during the month before the baseline assessment, which was identified by the following: if they 1) had experienced LBP that lasted for more than a day; and 2) had reported that doing their normal jobs was "difficult" or "impossible". Participants were excluded if they had changed jobs during the follow-up period.

Descriptive statistics were calculated for each factor. To assess the associations between a risk factor and chronic disabling LBP, univariate and multivariate logistic regression analyses were conducted. First, crude odds ratios (ORs) and 95\% confidence intervals (CIs) were calculated for each factor. We included factors with $p$-values $<0.1$ in the univariate logistic analysis in a multivariate logistic regression model. The stepwise method was used to select factors with statistical significance at $p<0.1$. To examine the combination effect of psychosocial factors identified in the multivariate logistic regression analyses, a frequency table of chronic disabling LBP was constructed by stratifying psychosocial factors.

All statistical analyses were performed using SAS Re-

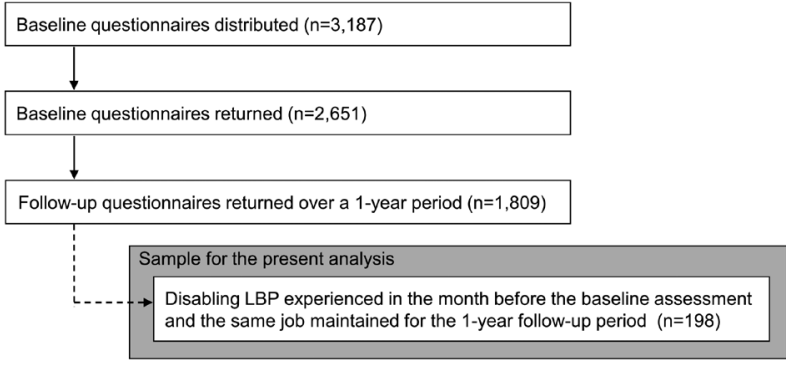

Fig. 1. Flow chart of the sample selection process. LBP: low back pain.

lease 9.3 (SAS Institute, Cary, NC, USA).

\section{Results}

\section{Baseline characteristics of the study participants}

Of 1,809 participants who responded to the $1 \mathrm{yr}$ followup questionnaire, the present analysis included 198 participants (Fig. 1). The mean (standard deviation [SD]) age at baseline was 36.0 (9.1) yr; the majority (69.0\%) were male. The mean (SD) BMI at baseline was 22.2 (3.0) $\mathrm{kg} / \mathrm{m}^{2}$. The percentages of participants belonging to each occupational group were as follows: nurses $(29.3 \%)$, office workers $(5.6 \%)$, sales/marketing workers $(5.6 \%)$, transportation workers $(53.5 \%)$, and others $(6.1 \%)$.

\section{Frequency of chronic disabling LBP}

Of 198 participants, 35 (17.7\%) participants had chronic disabling LBP during the $1 \mathrm{yr}$ follow-up period. Of these, 33 participants $(94.3 \%$ ) had grade 2 LBP and the remaining two participants $(5.7 \%)$ had grade 3 LBP. The mean (SD) age at baseline of these 35 participants was 36.6 (8.0) yr; the majority (74.3\%) were male. The mean (SD) BMI at baseline was $23.3(3.5) \mathrm{kg} / \mathrm{m}^{2}$.

\section{Associations between chronic disabling LBP and potential risk factors}

Table 1 summarizes the crude ORs and 95\% CIs for each factor. The results revealed that age, obesity (BMI $\geq 25 \mathrm{~kg} / \mathrm{m}^{2}$ ), excessive working hours ( $\geq 60 \mathrm{~h}$ per week), somatizing tendency ( $\geq 2$ somatic symptoms), and expectation of LBP problems were potential risk factors of having chronic disabling LBP (ORs: 2.03-3.47, $p<0.1$ for all).

These five potential risk factors were entered into the multivariate logistic regression model. After stepwise selection, the interaction effect of two factors, expectation of LBP problems and excessive working hours ( $\geq 60 \mathrm{~h}$ per week), as well as these two factors were selected. The 
Table 1. Crude odds ratios of baseline factors for chronic disabling LBP

\begin{tabular}{|c|c|c|c|c|}
\hline Factor & Number of respondents & $\mathrm{n}(\%)$ & OR $(95 \% \mathrm{CI})$ & $p$-value \\
\hline Age (yr) & 193 & & & $0.05 *$ \\
\hline$\leq 39$ & & $134(69.4)$ & & \\
\hline $40-49$ & & $40(20.7)$ & $2.31(1.01-5.24)$ & \\
\hline$\geq 50$ & & $19(9.8)$ & $0.30(0.04-2.36)$ & \\
\hline Gender & 197 & & & 0.46 \\
\hline Male & & $136(69.0)$ & & \\
\hline Female & & $61(31.0)$ & $0.73(0.32-1.67)$ & \\
\hline BMI $\geq 25 \mathrm{~kg} / \mathrm{m}^{2}$ (obesity) & 193 & $30(15.5)$ & $2.37(0.97-5.76)$ & $0.06^{*}$ \\
\hline Current smoker & 198 & $109(55.1)$ & $0.73(0.35-1.51)$ & 0.40 \\
\hline$<5 \mathrm{~h}$ sleep per day & 196 & $27(13.8)$ & $1.10(0.38-3.14)$ & 0.86 \\
\hline Regular exercise $<$ once per week & 196 & $149(76.0)$ & $1.32(0.54-3.26)$ & 0.54 \\
\hline Finished full-time education at $\leq 19 \mathrm{yr}$ & 196 & $98(50.0)$ & $0.61(0.29-1.29)$ & 0.19 \\
\hline Past history of LBP & 193 & $179(92.7)$ & $2.94(0.37-23.23)$ & 0.31 \\
\hline Employed in current job for $<1 \mathrm{yr}$ & 198 & $16(8.1)$ & $0.29(0.04-2.27)$ & 0.57 \\
\hline Use a keyboard for $\geq 4 \mathrm{~h}$ & 197 & $35(17.8)$ & $1.55(0.63-3.79)$ & 0.24 \\
\hline Move wrist/finger for $\geq 4 \mathrm{~h}$ & 198 & $66(33.3)$ & $0.90(0.41-1.97)$ & 0.79 \\
\hline Bend elbow for $\geq 1 \mathrm{~h}$ & 196 & $154(78.6)$ & $1.72(0.62-4.75)$ & 0.30 \\
\hline Hands above shoulder height for $\geq 1 \mathrm{~h}$ & 197 & $55(27.9)$ & $1.44(0.66-3.15)$ & 0.36 \\
\hline Lift weights of $\geq 25 \mathrm{~kg}$ by hand & 196 & $149(76.0)$ & $0.89(0.39-2.07)$ & 0.79 \\
\hline Kneel/squat for $\geq 1 \mathrm{~h}$ & 197 & $107(54.3)$ & $0.76(0.36-1.57)$ & 0.45 \\
\hline Stand for $\geq 4 \mathrm{~h}$ & 196 & $138(70.4)$ & $1.06(0.47-2.38)$ & 0.88 \\
\hline Twist back/stoop for $\geq 4 \mathrm{~h}$ & 197 & $121(61.4)$ & $1.25(0.58-2.69)$ & 0.57 \\
\hline Drive for $\geq 4 \mathrm{~h}$ & 197 & $86(43.7)$ & $0.72(0.34-1.53)$ & 0.39 \\
\hline Work $\geq 60$ h per week & 194 & $83(42.8)$ & $2.03(0.97-4.26)$ & $0.06^{*}$ \\
\hline Irregular work shift (nighttime shift) & 196 & $87(44.4)$ & $0.60(0.28-1.28)$ & 0.19 \\
\hline Interpersonal stress at work & 197 & $130(66.0)$ & $0.55(0.26-1.15)$ & 0.11 \\
\hline Inadequate breaks at work & 197 & $156(79.2)$ & $0.71(0.30-1.67)$ & 0.43 \\
\hline Lack of control over how to work & 198 & $95(48.0)$ & $1.03(0.50-2.14)$ & 0.94 \\
\hline Lack of control over what to do at work & 198 & $82(41.4)$ & $1.08(0.51-2.25)$ & 0.85 \\
\hline Lack of workplace support & 194 & $27(13.9)$ & $1.74(0.67-4.50)$ & 0.26 \\
\hline Dissatisfied with job & 198 & $131(66.2)$ & $1.14(0.52-2.50)$ & 0.74 \\
\hline Aware of colleagues with LBP & 198 & $185(93.4)$ & $0.70(0.18-2.68)$ & 0.60 \\
\hline Emotional trauma in childhood & 193 & $32(16.6)$ & $0.84(0.30-2.37)$ & 0.75 \\
\hline$\geq 2$ distressing somatic symptoms & 196 & $69(35.2)$ & $2.28(1.09-4.79)$ & $0.03 *$ \\
\hline Low mood & 195 & $96(49.2)$ & $0.97(0.47-2.01)$ & 0.93 \\
\hline Expect that LBP would become a problem & 198 & $100(50.5)$ & $3.47(1.53-7.88)$ & $0.00 *$ \\
\hline
\end{tabular}

LBP: low back pain; OR: odds ratio; CI: confidence interval; BMI: body mass index. $* p<0.1$.

results of the multivariate logistic regression model are shown in Table 2.

A frequency table of chronic disabling LBP stratified by these two risk factors is shown in Table 3 . Chronic disabling LBP was reported in $42.5 \%$ of participants with expectation of LBP problems and excessive working hours ( $\geq 60 \mathrm{~h}$ per week), which was approximately 3.5 -fold higher than the rate among participants without expectation of LBP problems and excessive working hours (11.8\%).

\section{Discussion}

The current study was conducted to corroborate our previous findings from the $1 \mathrm{yr}$ prospective cohort study and further explore the risk factors of chronic disabling LBP. The results revealed that the frequency of chronic disabling LBP in the current study was similar to that reported in our previous study $(17.7 \%$ in the current study and $17.0 \%$ in our previous study ${ }^{15)}$ ). In accord with our previous findings, the present results indicated that psychosocial factors 
Table 2. Results of multivariate logistic regression model

\begin{tabular}{lcccc}
\hline \multicolumn{1}{c}{ Risk factor } & Coefficient & SE & Wald $\chi^{2}$ & $p$-value \\
\hline Intercept & 1.6605 & 0.2208 & 56.5425 & $<0.0001$ \\
Expect that LBP would become a problem & 0.6421 & 0.2208 & 8.4539 & 0.0036 \\
Work $\geq 60$ h per week & 0.2142 & 0.2208 & 0.9412 & 0.3320 \\
Interaction (expectation * work $\geq 60 \mathrm{~h}$ ) $^{\mathrm{a}}$ & -0.5019 & 0.2208 & 5.1661 & 0.0230 \\
\hline
\end{tabular}

SE: standard error; LBP: low back pain.

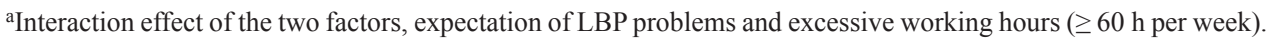

The factor, excessive working hours, was left in the model as it is a main effect of this interaction.

Table 3. Frequency table of chronic disabling LBP stratified by psychosocial factors

\begin{tabular}{ccccc}
\hline \multicolumn{2}{c}{ Risk factor } & & \multicolumn{2}{c}{ Chronic disabling LBP } \\
\cline { 1 - 2 } \cline { 4 - 5 } $\begin{array}{c}\text { Expect that LBP would } \\
\text { become a problem }\end{array}$ & Work $\geq 60$ h per week & & $\begin{array}{c}\text { No } \\
\mathrm{n}(\%)\end{array}$ & $\begin{array}{c}\text { Yes } \\
\mathrm{n}(\%)\end{array}$ \\
\hline No & $<60 \mathrm{~h}$ & & $45(88.2)$ & $6(11.8)$ \\
& $\geq 60 \mathrm{~h}$ & & $40(93.0)$ & $3(7.0)$ \\
Yes & $<60 \mathrm{~h}$ & & $51(85.0)$ & $9(15.0)$ \\
& $\geq 60 \mathrm{~h}$ & $23(57.5)$ & $17(42.5)$ \\
\hline
\end{tabular}

LBP: low back pain.

are potential risk factors for chronic disabling LBP. Thus, we confirmed that psychosocial factors appear to play a role for chronic disabling LBP, highlighting the need for a psychosocial approach for LBP management.

Among the range of factors examined, a combination of psychosocial factors, particularly excessive working hours and the expectation of LBP problems, were important risk factors for chronic disabling LBP. Each of these factors (or closely related factors) are known to contribute to LBP development $^{22,28)}$, symptom chronicity ${ }^{29,30)}$ and disability ${ }^{31)}$. For instance, because an excessive number of working hours was reported to elevate the risk of musculoskeletal disorders such as $\mathrm{LBP}^{28)}$ and has been associated with new onset of disabling $\mathrm{LBP}^{22)}$, this factor might have triggered new disabling LBP onset in the current study. Regarding expectation of LBP problems, a previous study reported that expectations of pain can contribute to symptom chronicity ${ }^{29)}$. Furthermore, significant relationships were found between persistence of pain and negative expectations about pain in the next year ${ }^{30}$. Adverse beliefs about prognosis are reported to be associated with persistent disabling musculoskeletal pain and the transition from non-disabling to disabling musculoskeletal pain ${ }^{31)}$. In light of these previous findings, it is suggested that excessive working hours may have contributed to triggering new onset of disabling LBP, and the expectation of LBP problems may have contributed to symptom chronicity and disability.

Although factors related to physical and psychosocial workload were not directly associated with chronic disabling LBP in the current study, excessive working hours may partially reflect the presence of "workaholism", implying a possible association between physical and psychosocial workload and chronic disabling LBP. Workaholism is known as a risk factor for disabling back pain ${ }^{32}$. In addition, workaholism may hinder parts of the recovery process, such as "psychological detachment"33) (i.e., disengaging oneself psychologically from work during non-work time, to distance oneself from a job in both a physical and a psychological sense $\mathrm{e}^{34-36)}$ ). A low level of psychological detachment has been reported to elevate LBP probability when work stressors are increased ${ }^{37}$. Some participants with excessive working hours in the current study may have been in a state of low psychological detachment due to possible workaholism, resulting in insufficient recovery, and potentially contributing to LBP in these participants.

Dysfunction in the mesolimbic dopaminergic system, which controls both pain and pleasure ${ }^{38,39)}$ may partially explain the association between chronic disabling LBP and a combination of psychosocial factors. The mesolimbic dopamine system is stimulated to suppress pain when a person experiences painful stimuli; however, exposure to chronic stress (e.g., anxiety or distress) has been suggested to result in hyperalgesia due to the dysfunction of mesolimbic dopamine mechanisms ${ }^{38,39)}$. Our previous study revealed that hyperalgesia resulting from chronic stress due to dissatisfaction with life and work can lead to chronic 
disabling $\mathrm{LBP}^{15)}$. In the current study, more than $40 \%$ of participants with an expectation of LBP problems and excessive working hours had chronic disabling LBP. These participants may have been under stress, which could lead to mesolimbic dopaminergic dysfunction, potentially leading to chronic disabling LBP.

Several limitations of the current study should be acknowledged. First, the generalizability of our results may be limited, and our findings may not be entirely applicable to the general population of Japanese workers because we recruited participants from a limited range of occupations in or near Tokyo. Second, some degree of misclassification was inevitable in the current study, as exposures and symptoms were assessed with self-report questionnaires. The use of objective measures for physical exposure (e.g., heavy lifting) may provide a more accurate assessment. Because the length of the questionnaire was limited, we identified interpersonal stress using a single question as a substitute for the longer Brief Job Stress Questionnaire ${ }^{40)}$, which we used for assessment of psychosocial factors, including interpersonal stress, in our earlier study ${ }^{15)}$. Additionally, the possibility of recall bias could not be avoided because of the nature of self-report questionnaires. For instance, we retrospectively identified the presence and severity of LBP at baseline and follow-up. It is possible that the participants in this study with blue collar jobs were more likely to recall symptoms and difficulty with work. Third, the analysis was conducted with a relatively small study sample. Additionally, the relatively infrequent outcome (having chronic disabling LBP during the followup period) restricted the statistical power of our analysis. Therefore, the results should be interpreted with caution. However, it should be noted that the frequency of chronic disabling LBP in the present study was consistent with our previous findings ${ }^{15}$. Finally, we cannot exclude the possibility that unrecognized factors may have affected chronic disabling LBP development, even though we included a range of risk factors and potential risk factors for chronic disabling LBP reported in previous studies, such as depression and somatization ${ }^{9,10)}$.

In conclusion, the current results revealed that psychosocial factors play a key role for chronic disabling LBP, as suggested in our previous study ${ }^{15}$. A combination of psychosocial factors, particularly the expectation of LBP problems and excessive working hours, were likely to affect chronic disabling LBP among various factors. Consistent with previous studies, the current findings highlight the need for a psychosocial treatment approach to prevent and address chronic disabling LBP in Japanese workers under stress.

\section{Acknowledgments}

We thank Dr. David Coggon and Dr. Keith T. Palmer for organizing and leading the CUPID study, and CUPID collaborators, particularly Dr. Noriko Yoshimura, for their contributions to the study. The current study was part of clinical research projects funded by the Japan Labour Health and Welfare Organization.

\section{References}

1) Vos T, Flaxman AD, Naghavi M, Lozano R, Michaud C, Ezzati M, Shibuya K, Salomon JA, Abdalla S, Aboyans $\mathrm{V}$, et al. (2012) Years lived with disability (YLDs) for 1160 sequelae of 289 diseases and injuries 1990-2010: a systematic analysis for the Global Burden of Disease Study 2010. Lancet 380, 2163-96. [Medline] [CrossRef]

2) Japan Ministry of Health, Labour and Welfare. Comprehensive Survey of Living Conditions 2016. http:// www.mhlw.go.jp/toukei/saikin/hw/k-tyosa/k-tyosa16/dl/04. pdf. (in Japanese) Accessed November 8, 2017.

3) Fujii T, Matsudaira K (2013) Prevalence of low back pain and factors associated with chronic disabling back pain in Japan. Eur Spine J 22, 432-8. [Medline] [CrossRef]

4) Deyo RA, Rainville J, Kent DL (1992) What can the history and physical examination tell us about low back pain? JAMA 268, 760-5. [Medline] [CrossRef]

5) Deyo RA, Weinstein JN (2001) Low back pain. N Engl J Med 344, 363-70. [Medline] [CrossRef]

6) Itz CJ, Geurts JW, van Kleef M, Nelemans P (2013) Clinical course of non-specific low back pain: a systematic review of prospective cohort studies set in primary care. Eur J Pain 17, 5-15. [Medline] [CrossRef]

7) Becker A, Held H, Redaelli M, Strauch K, Chenot JF, Leonhardt C, Keller S, Baum E, Pfingsten M, Hildebrandt J, Basler HD, Kochen MM, Donner-Banzhoff N (2010) Low back pain in primary care: costs of care and prediction of future health care utilization. Spine 35, 1714-20. [Medline] [CrossRef]

8) Krismer M, van Tulder M, Low Back Pain Group of the Bone and Joint Health Strategies for Europe Project (2007) Strategies for prevention and management of musculoskeletal conditions. Low back pain (non-specific). Best Pract Res Clin Rheumatol 21, 77-91. [Medline] [CrossRef]

9) Pincus T, Burton AK, Vogel S, Field AP (2002) A systematic review of psychological factors as predictors of chronicity/disability in prospective cohorts of low back pain. Spine 27, E109-20. [Medline] [CrossRef]

10) Pincus T, McCracken LM (2013) Psychological factors and treatment opportunities in low back pain. Best Pract Res Clin Rheumatol 27, 625-35. [Medline] [CrossRef]

11) Turk DC, Rudy TE (1992) Classification logic and strategies in chronic pain. In: Handbook of Pain 
Assessment, Turk DC and Melzack R (Eds.), 409-28, Guildford press, New York.

12) Williams RA, Pruitt SD, Doctor JN, Epping-Jordan JE, Wahlgren DR, Grant I, Patterson TL, Webster JS, Slater MA, Atkinson JH (1998) The contribution of job satisfaction to the transition from acute to chronic low back pain. Arch Phys Med Rehabil 79, 366-74. [Medline] [CrossRef]

13) Thomas E, Silman AJ, Croft PR, Papageorgiou AC, Jayson MI, Macfarlane GJ (1999) Predicting who develops chronic low back pain in primary care: a prospective study. BMJ 318, 1662-7. [Medline] [CrossRef]

14) McMahon MJ, Gatchel RJ, Polatin PB, Mayer TG (1997) Early childhood abuse in chronic spinal disorder patients. A major barrier to treatment success. Spine 22, 2408-15. [Medline] [CrossRef]

15) Matsudaira $K$, Kawaguchi M, Isomura $T$, Inuzuka $K$, Koga $T$, Miyoshi K, Konishi H (2015) Assessment of psychosocial risk factors for the development of non-specific chronic disabling low back pain in Japanese workers-findings from the Japan Epidemiological Research of Occupation-related Back Pain (JOB) study. Ind Health 53, 368-77. [Medline] [CrossRef]

16) Coggon D, Ntani G, Palmer KT, Felli VE, Harari R, Barrero LH, Felknor SA, Gimeno D, Cattrell A, Serra C, et al. (2012) The CUPID (Cultural and Psychosocial Influences on Disability) study: methods of data collection and characteristics of study sample. PLoS One 7, e39820. [Medline] [CrossRef]

17) Coggon D, Ntani G, Vargas-Prada S, Martinez JM, Serra C, Benavides FG Palmer KT, Members of CUPID Collaboration (2013) International variation in absence from work attributed to musculoskeletal illness: findings from the CUPID study. Occup Environ Med 70, 575-84. [Medline] [CrossRef]

18) Coggon D, Ntani G, Palmer KT, Felli VE, Harari R, Barrero LH, Felknor SA, Gimeno D, Cattrell A, Vargas-Prada S, et al. (2013) Patterns of multisite pain and associations with risk factors. Pain 154, 1769-77. [Medline] [CrossRef]

19) Matsudaira K, Palmer KT, Reading I, Hirai M, Yoshimura N, Coggon D (2011) Prevalence and correlates of regional pain and associated disability in Japanese workers. Occup Environ Med 68, 191-6. [Medline] [CrossRef]

20) Fujii T, Matsudaira K, Yoshimura N, Hirai M, Tanaka $S$ (2013) Associations between neck and shoulder discomfort (Katakori) and job demand, job control, and worksite support. Mod Rheumatol 23, 1198-204. [Medline] [CrossRef]

21) Sawada $T$, Matsudaira $K$, Muto $Y$, Koga $T$, Takahashi $M$ (2016) Potential risk factors for onset of severe neck and shoulder discomfort (Katakori) in urban Japanese workers. Ind Health 54, 230-6. [Medline] [CrossRef]

22) Kawaguchi M, Matsudaira K, Sawada T, Koga T, Ishizuka A, Isomura T, Coggon D (2017) Assessment of potential risk factors for new onset disabling low back pain in
Japanese workers: findings from the CUPID (cultural and psychosocial influences on disability) study. BMC Musculoskelet Disord 18, 334. [Medline] [CrossRef]

23) Von Korff M, Ormel J, Keefe FJ, Dworkin SF (1992) Grading the severity of chronic pain. Pain 50, 133-49. [Medline] [CrossRef]

24) Fukuhara S, Bito S, Green J, Hsiao A, Kurokawa K (1998) Translation, adaptation, and validation of the SF-36 Health Survey for use in Japan. J Clin Epidemiol 51, 1037-44. [Medline] [CrossRef]

25) Fukuhara S, Ware JE Jr, Kosinski M, Wada S, Gandek B (1998) Psychometric and clinical tests of validity of the Japanese SF-36 Health Survey. J Clin Epidemiol 51, 1045-53. [Medline] [CrossRef]

26) Yamazaki S, Fukuhara S, Green J (2005) Usefulness of five-item and three-item Mental Health Inventories to screen for depressive symptoms in the general population of Japan. Health Qual Life Outcomes 3, 48. [Medline] [CrossRef]

27) Derogatis LR, Melisaratos N (1983) The brief symptom inventory: an introductory report. Psychol Med 13, 595-605. [Medline] [CrossRef]

28) Koda S, Yasuda N, Sugihara Y, Ohara H, Udo H, Otani T, Hisashige A, Ogawa T, Aoyama H (2000) [Analyses of work-relatedness of health problems among truck drivers by questionnaire survey]. Sangyo Eiseigaku Zasshi 42, 6-16 (in Japanese). [Medline] [CrossRef]

29) Palmer KT, Reading I, Linaker C, Calnan M, Coggon D (2008) Population-based cohort study of incident and persistent arm pain: role of mental health, self-rated health and health beliefs. Pain 136, 30-7. [Medline] [CrossRef]

30) Sadeghian F, Raei M, Amiri M (2014) Persistent of neck/ shoulder pain among computer office workers with specific attention to pain expectation, somatization tendency, and beliefs. Int J Prev Med 5, 1169-77. [Medline]

31) Vargas-Prada S, Martínez JM, Coggon D, Delclos G, Benavides FG, Serra C (2013) Health beliefs, low mood, and somatizing tendency: contribution to incidence and persistence of musculoskeletal pain with and without reported disability. Scand J Work Environ Health 39, 589-98. [Medline] [CrossRef]

32) Matsudaira K, Shimazu A, Fujii T, Kubota K, Sawada T, Kikuchi N, Takahashi M (2013) Workaholism as a risk factor for depressive mood, disabling back pain, and sickness absence. PLoS One 8, e75140. [Medline] [CrossRef]

33) Kubota K, Shimazu A, Kawakami N (2014) Association of workaholism and work engagement with recovery experiences among Japanese workers. Jpn J Behav Med 20, 69-76 (in Japanese).

34) Sonnentag S, Bayer UV (2005) Switching off mentally: predictors and consequences of psychological detachment from work during off-job time. J Occup Health Psychol 10, 393-414. [Medline] [CrossRef]

35) Sonnentag S, Fritz C (2007) The Recovery Experience Questionnaire: development and validation of a measure for 
assessing recuperation and unwinding from work. J Occup Health Psychol 12, 204-21. [Medline] [CrossRef]

36) Sonnentag S (2012) Psychological detachement from work during leisure time: the benefits of mentally disengaging from work. Psychol Sci 21, 114-8.

37) Mierswa T, Kellmann M (2017) Psychological detachment as moderator between psychosocial work conditions and low back pain development. Int J Occup Med Environ Health 30, 313-27. [Medline]

38) Wood PB (2006) Mesolimbic dopaminergic mechanisms and pain control. Pain 120, 230-4. [Medline] [CrossRef]

39) Leknes S, Tracey I (2008) A common neurobiology for pain and pleasure. Nat Rev Neurosci 9, 314-20. [Medline] [CrossRef]

40) Shimomitsu T, Yokoyama K, Ono Y, Maruta T, Tanigawa $\mathrm{T}(1998)$ Development of a novel brief job stress questionnaire. In: Report of the research grant for the prevention of workrelated diseases from the Ministry of Labour, Kato S (Ed), 107-15, Japanese Ministry of Labour, Tokyo. 